\title{
On the Relationship between Indirectness and Politeness
}

\author{
Jimei Li \\ Xi’an Innovation College \\ Yan'an University \\ Xi'an, China
}

\begin{abstract}
It is generally believed that moderate indirectness is better and more easily acceptable than blunt and direct speech acts among both close friends and other acquaintances in everyday conversations, especially among strangers. Such indirect speech acts mean comparatively more politeness for the speech acts recipient. It is not at all an unusual phenomenon in everyday life. This paper focuses on exposure of how indirect speech act coming into being in terms of speech act theory and cooperative principles. It illustrates essential causes from the perspective of politeness, showing that communicators can utilize indirect speech acts to help convey their politeness to speech acts receivers so as to accomplish communicative purposes, facilitate interpersonal communication and maintain interpersonal relationship with mutual respect, to certain extent.
\end{abstract}

Keywords-indirectness; indirect speech act; implicature; politeness

\section{INTRODUCTION}

We are living in a world, where everyone maybe in need of others. Compared with a direct command or a disagreeable order to ask for help from people around us, it is quite obvious that an indirect request would be a safer strategy. It shows that utterance speaker is comparatively more polite and considerate for both parties' sake in conversations. It reduces the chances of losing face for the speaker when facing possible decline from the other party and it also leaves more room for the other party to respond for the request of the speaker according to their actual situations. Such indirect speech act is a very common linguistic phenomenon in our everyday verbal communication among friends and other acquaintances, and we tend to express our intentions indirectly instead of being blunt, especially in making such a request. It is considered as a sign of politeness in interpersonal communication and it may help maintain harmonious social relationship among people.

This paper will firstly explain indirect speech act phenomenon in terms of speech act theory, cooperative principle and then present the significance of using indirect speech act for politeness. In order to save the faces of both parties during conversations, people tend to apply indirect speech acts even among friends. It can be inferred that the more indirect the utterances are; the more courtesy a speaker tries to show in front of a listener. Therefore, indirectness and politeness are closely related to each other. We could actually infer people's interpersonal relationship according to how indirectly a person speaks to another.

\section{INDIRECT SPEECH ACT}

\section{A. Definition of Indirect Speech Act}

Indirectness and directness are antonyms. When we take a look at indirect speech act, we can never neglect direct speech act, since they are complementary antonyms, to be more exact. Direct speech act is defined as "there is direct relationship between a structure and a function.” [2]. It means that there is one-to-one relationship between the structure and the function. There are generally three basic forms of structure: declarative, interrogative and imperative as well as three correspondent communicative functions: statement, question, and command/request. For example:

(1) He is my husband. (declarative for a statement)

(2) Are you serious? (interrogative for a question)

(3) Shut up! (imperative for a command)

Yule then defines indirect speech act as "there is indirect relationship between a structure and a function.” [2]. For example:

(4) It is noisy here.

(5) I hereby tell you that it is noisy here.

(6) I hereby request of you that you turn down your radio a little bit.

(7) Could you turn down your radio a little bit?

In the example (4), there are two functions when the speaker utters this declarative. Namely, on one hand the speaker just means what he or she expresses which is shown in (5). On the other hand, speaker means to show his or her conceived intention that the noise has already interrupted him or her, hoping that the listener or hearer could turn down the radio in (6). We can see obviously that (5) is the literal meaning or semantic meaning of example (4), while (6) is intended meaning of the speaker. The example (7) presents a request by uttering an interrogative. The speaker does not want a yes/no answer. Instead, the speaker wants the hearer to perform the action of turning down the radio rather than admit or deny his or her ability. Therefore, we conclude that (4) and (7) are indirect speech act.

However, a problem then arises. How does the hearer tell whether the speaker means (5) or (6) when only hear the utterance of (4) "Searle views indirect speech acting as a combination of two acts, a primary illocutionary act and a secondary one, where the primary act operates through, and in 
force of, the secondary one.” [3]. In order to solve this problem Searle builds a ten-step pyramid of reasoning. He thinks that speaker can convey his implicature on the basis of mutual understanding including language, non-linguistic background knowledge and the capability of inference of the hearer during performing indirect speech act [4]. For example:

(8) A: Let's go skating tomorrow.

B: I have an exam tomorrow.

No matter what B says is true or not, both A and B know exactly that exam is much more important than go skating and it will take some time to prepare, so B successfully conveys his intention to A without disappointing A by using direct speech act of saying "no" and explaining the reason very clearly. It shows that B understands A's kind invitation and gives further understandable explanation instead of using direct speech act of refusal so as to save the invitation giver's face, which is more polite verbal utterance and more acceptable social conduct in human communication among friends.

\section{B. Bi-functionality of Indirect Speech Act}

Besides, we should not neglect the bi-functionality of indirect speech act in daily communication. We have already known that indirect speech act involves literal meaning and intended meaning, implicature. Therefore, one indirect utterance such as an order or a request will be of bifunctionality [9]. It can cause misunderstanding or even humor. For example:

(9) Mother: That window is still open. Son: Yes, it is.

The mother expresses her intention by a statement rather than a direct order or request. The naughty son just neglects real intended meaning of the mother, and agrees with the statement of the mother's without performing the action of closing the door. This is the first explanation, a normal conversation, where the Mother may expect more explanation, or an act of closing the window from her son. The speaker also expects the listener to get the real intention. Secondly, humorous effect is generated, when the real intention is not conveyed to the hearer. The son takes only literal meaning and responds literally, ignoring the implicature of his mother intentionally or unintentionally. Thirdly, the utterance "Yes, it is" is better than direct refusal "I don't want to close the door" to his mother's indirect request.

(10) A: You look tired, I can drive you home. B: Oh, no. I'm fine.

Similar to the previous example, there can be different explanations. Firstly, A actually wants to send B home by saying that B is tired, while B takes it seriously. B is so honest that he states his statement by saying "fine". B in fact misunderstands A's indirect speech act of showing concern. The guest is so frank that he cannot find a white lie to refuse the host and hostess' hospitality. Secondly, B honestly refuses A's offer for help. Since there is no specific communicative context, we can interpret it in different ways, which increase the difficulty in understanding the utterance. Hence, such bifunctionality may be distinguished and cleared based on mutual understanding in certain contextual situation.

\section{Indirect Speech Act Theory}

Such Indirect speech act is as a matter of fact based on speech act theory. It is very necessary to mention some about speech act theory. It is Austin who launched his theory first in a set of lectures and then published in 1962 as How to Do Things with Words. He noted that some ordinary language declarative sentence contrary to logical positivist assumptions, are not apparently used with any intention of making true or false statements, which he called constatives, but do things. Austin termed these utterances as performatives. He set up a series of felicity conditions, under which performatives will come off. Violation of these conditions will cause misfires or abuses. Later, there are two crucial sliding definitions: explicit performatives and implicit performatives. Using adverb "hereby" separates performative verbs from others. Besides, all the implicit performatives can be put into the form of an explicit performatives. Secondly, there is a shift from dichotomy performative/constative to a general theory of illocutionary acts, of which the various performatives and constatives are just sub-cases. He put forward locutionary act, illocutionary act and perlocutionary act with illocutionary act as its core [7].

Searle later classified the illocutionary acts into five types: 1. Representatives 2. Directives 3. Commissives 4. Expressives 5. Declarations [8].

All those illocutionary acts express the speakers' intention, while among others many speakers would like to choose indirect ways, which lead the hearers to infer their real intentions.

\section{ANALYSIS OF INDIRECT SPEECH ACT FROM COOPERATIVE PRINCIPLE}

Now we can analyze such indirect speech acts from cooperative principle. Grice identifies as guidelines of four basic maxims of conversation or general principles underlying the efficient cooperative use of language, which jointly express a general cooperative principle. These principles are expressed as follows:

The cooperative principle: make your contribution such as is required, at the stage at which it occurs, by the accepted purpose or direction of the talk exchange in which you are engaged

1) The maxim of Quality

Try to make our contribution one that is true, specifically:

a) do not say what you believe to be false

b) do not say that for which you lack adequate evidence

2) The maxim of Quantity

a) make your contribution as informative as is required for the current purposes of the exchange

b) do not make your contribution more informative than is required.

3) The maxim of Relevance

make your contributions relevant

4) The maxim of Manner

Be perspicuous, and specifically:

a) avoid obscurity 
b) avoid ambiguity

c) be brief

d) be orderly [6].

Any flout of these principles will cause implicature, and indirect speech acts are typical examples of flouts of principles.

Now take another look at above example (8). We have known that when A offers a request to go skating, B refuses by saying that there will be an exam the next day. We can infer that $\mathrm{B}$ maybe violates the maxim of quality by a white lie that is false, and also it violates the maxim of relevance since there is no direct relationship between skating and exam. B utters this sentence so as not to refuse A's invitation directly and impolitely at that moment. By seemingly non-relevant response, B successfully conveys the implicature of a decline. Take another example.

(11) A: Could you lend me some money?

B: I spend all my savings on clothes, and perfumes. You know I really regret now, and I have to pay the rent of my apartment this month...

If A has ever tried to borrow some money and has been given such a long and tedious answer. A knows exactly that there is no single slight hope. A can sense that it is a kind of refusal. We can know by intuition that $B$ violates the maxim of quality that B may only tell white lies; B violates the maxim of quantity by adding unnecessary information more than required; $\mathrm{B}$ violates the maxim of relevance by saying something that has nothing to do with the present topic; B violates the maxim of manner giving an unclear reply. We can reason that there are some implicature in B's reply via using indirect speech acts instead of direct speech act of saying "no".

\section{USING INDIRECT SPEECH ACT FOR POLITENESS}

Most of us may give vote to indirect speech acts. "The occurrence of the imperative in orders or requests is dispreferred in many languages, including English, despite its status as the 'genuine' expression of the speech act 'order' or 'request'." [3]. Levinson remarks that "most usages of requests are indirect" [6], whereas "imperatives are rarely used to command or request" [6]; in the same vein, Thomas observes that "in English, it is not usual to use the words I invite you to perform the act of inviting” [5].

There are a lot of reasons why we tend to use indirect speech acts especially for requests and orders. It is because that requests and orders are considered as directives according to Searle's classification and they are considered highly competitive according to Leech's, which directly threaten the face of people involved in a conversation. Leech put forward six maxims known as polite principle from the aspects of "cost" and "benefit" in a broadest sense: 1. Tact maxim 2. Generosity maxim 3. Approbation maxim 4. modesty maxim 5. Agreement maxim 6. Sympathy maxim [1].

It means that people tend to follow such maxims in daily conversations unconsciously or consciously most of the time, and we do know that people talk trying to "minimize" one's own "benefit" and "maximize" the other's "cost" to be more polite. It is mutually understood as a more acceptable and expected social conduct from both parties involved in a comfortable conversation or exchange. Hence, the one who violates such maxims would be considered rude.

These maxims explain why some utterances are comparatively polite; some are not so polite and some others are impolite which are shown by anomalous language use [9]. In these six maxims, the most basic one is the first maxim. It is because that tact maxim is used for directives, while directives can particularly reflect politeness and need it most [9]. As we have mentioned above, requests and orders belong to directives. Now we set example of tact maxim, which is to minimize the cost of other, or maximize the benefit of other:

(12) Would it be possible for you to spare a minute?

(13) Could you spare a minute?

(14) Will you spare a minute?

(15) Lend me your ears!

(16) You must listen to me.

This series of requests that convey the same message, we can sense by intuition that the requests become more and more impolite from top to the bottom. Example (12) is the most polite one, while (16) is the most impolite one. Example (12) contains such auxiliary verb "would" and possibility word "possible" leaving enough room for the listener to make their choices. Example (16) is an order with auxiliary verb "must". This series of expressions is arranged from the one that minimizes the cost of other to the one that maximizes the benefit of other. It is a large set of expressions we can choose according to different situations or contexts. Under different circumstances, we can't neglect “appropriateness of language"[9]. The polite ones are comparatively more desirable expressions for most occasions, but even among the polite utterances, we still need to make best choice according to different speech contexts.

Ervin-Tripp, $\mathrm{S}$ has made researches about the differences of indirect requests and to what kind of degree they differ from each other. She analyzes that the degree of familiarity decides the way people speak. For example:

(17) Would you mind my opening the window?

If someone utters this to a friend, his friend will surely wonders that there is something wrong with this guy, or the speaker just means to tell a friend that they are not intimate enough, or they are just kidding with each other by pretending to be polite. There would be more than one interpretation. These interpretations could be narrowed down, depending on different speech contexts. The context would define which interpretation is more applicable. However, it is indeed very polite to speak like this to a stranger or the one that is not familiar to the speaker.

\section{(18) Shut the door!}

This utterance is an obvious order, which definitely cannot be used to a superior boss or an elder person, if you are only a clerk or a youth. You would be fired except that you have good terms with your boss. You would be considered as spoiled younger generation and lack manners. However, you can say it to your intimate friend who knows your personality well and will never mind your direct manner and even enjoy your directness. Actually, for most of occasions, even among best friends, such utterances are not always desirable. 
Therefore, we can only possibly infer the relationship between speakers and listeners based on how directly or indirectly they speak to each other. While it is not a policy that can be applied to all circumstances, since we all know that even among best friends, we should not take directness for granted. We have to be aware when it is appropriate to show our politeness by using indirect speech acts, in order to save both parties' faces, showing our good manners and smooth mutual communication.

\section{CONCLUSION}

In everyday communication, people talk differently based on different education backgrounds or for different purposes, etc. Some prefer direct requests and others indirect ones. This paper explains the indirect speech act from two theories: speech act theory of Austin and Searle as well as cooperative principle of Grice, we can see that indirect speech act is common though, it needs painstaking analysis to expose the features of them. Among lots of reasons, we apply politeness principle of Leech to explain the fundamental reason of using indirect speech for politeness. That is why we would like to choose indirect speech acts rather than the others. We generally admit that being polite is presupposition of communication. No one wants to talk with those who always use vulgar words all day long. No one is willing to be imposed to perform certain actions. No one deliberately violates this universal truth of mutual respect.

In addition, there are a large number of forms of indirect speech acts that contain profound implicatures. A structure of linguistic forms can be blessed with quite different functions and the same function can be exercised by quite different structures. All of them can fully convey a speaker's intentions on the basis of common ground and shared knowledge. Usually it is believed that the more indirect the more polite among strangers or acquaintances, while it could be unusual among friends sometimes. Therefore, the interpretations of them are of great importance to improve one's communicative competence, and maintain harmonious social relationship among people.

\section{REFERENCES}

[1] G, Leech, Principles of Pragmatics. New York: Longman, 1983.

[2] G, Yule, Pragmatics. Shanghai: Shanghai Foreign Language Education Press, 2000

[3] J. L, Mey, Pragmatics: An introduction. Beijing: Foreign Language Teaching and Research Press, 2001.

[4] J, Searle, Indirect Speech Acts. New York: Academic Press, 1975.

[5] J, Thomas, Meaning in Interaction: An Introduction to Pragmatic. London and New York: Longman, 1995.

[6] S. C, Levinson, Pragmatics. Cambridge: Cambridge University Press, 1983.

[7] S. C, Levinson, Pragmatics. Beijing: Foreign Language Teaching and Research Press, 2001.

[8] Weidong, Dai, A New Concise Course on Linguistics for Students of English. Shanghai: Shanghai Foreign Language Education Press, 2002.

[9] Zhaoxiong, He, Pragmatics. Shanghai: Shanghai Foreign Language Education Press, 1999. 